\title{
In-Vitro evaluation of xanthine oxidase inhibition and antioxidant capacity of water extracts of corn silk (Zea mays L.)
}

\author{
Fazilatun Nessa ${ }^{1 *}$, Saeed Ahmed Khan ${ }^{1}$, Susan George ${ }^{1}$ \\ 1 Department of Pharmaceutical Chemistry \& Natural Products, Dubai Pharmacy College for Girls, Dubai, UAE
}

\begin{abstract}
Corn silk are ascribed as stigmata of maize female flowers of Zea mays L. (Gramineae). In view of the health beneficial properties of corn silk this study was aimed to evaluate in-vitro antioxidant and xanthine oxidase (XO) inhibitory activities of two type's water extracts of corn silk with different sample sizes and compared amongst them in order to choose a mode of extract preparation with higher antioxidant activity. $1 \%$ to $5 \%$ of microwave (MW-WCS; $2 \mathrm{~min}$ ) and hotplate heated (HP-WCS; $120^{\circ} \mathrm{C}, 30 \mathrm{~min}$ ) water extracts of corn silk were prepared and investigated spectrophotometrically to evaluate their free radical scavenging activity using $\mathrm{DPPH}^{{ }^{*}}$ and $\mathrm{ABTS}^{++}$as substrate, superoxide radical cation (enzymatically/non-enzymatically) scavenging activities and xanthine oxidase inhibitory activities respectively. Total polyphenols and total flavonoids contents of each extracts were determined and correlated with their antioxidant and XO inhibitory activities. The overall results of antioxidant and XO inhibition activities of water extracts were decreased in the order of: $5 \%>4 \%>3 \%>2 \%$ $>1 \%$. MC-WCS extracts were comparatively more potent than HP-WCS extracts in reduction of $50 \%$ free radicals, superoxide radicals and uric acid production. L-Ascorbic acid, Trolox, quercetin and allopurinol were used as reference compounds in this study. From the results it can be concluded that 2 min microwave heated corn silk tea/extract exhibited highest antioxidant and XO inhibitory activities due to their higher level of total polyphenols/flavonoid glycosides and Trolox equivalent antioxidant contents than their corresponding hotplate heated water extracts.
\end{abstract}

\section{Keywords:}

Corn silk, Microwave and hotplate heated water extracts, Polyphenols, Flavonoids, Antioxidant, Xanthine oxidase

\section{INTRODUCTION}

Corn silk appeared as yellowish/brownish silky fine soft thread and are ascribed as stigmata of corn or sweet corn. They are the female flowers of Zea mays $\mathrm{L}$. (corn) or Zea mays convar. saccharata var. rugose (sweet corn) from the family of Gramineae or Poaceae ${ }^{1}$. Silk and husk are usually removed and thrown away before boiling, steaming or roasting the corn. This waste product are considered as invaluable as traditionally raw silk are boiled in water and drink as tea to get benefit for condition related to urolithiasis ${ }^{2}$. Corn is cultivated in most part of the world. However, in United Arab Emirates, the unripe immature corn covered with husk and silk are available in the supermarket for consumer. As a folk medicine it is used in the bladder irritation of uric acid, gonorrhoea, phosphatic gravel and in hepatobiliary diseases ${ }^{3,4}$. Phytochemical review on corn silk revealed it contained a number of flavonoids, flavonoid glycosides namely 4'-dihydroxy-3'-methoxyflavone-7$O$-glucosides, 2"-O- $\alpha$-L-rhamnosyl-6-Cfucosylluteolin, $2 "-O-\alpha-\mathrm{L}-\mathrm{rhamnosyl}-6-\mathrm{C}-q u i n o v o s y l l u t e o l i n, \quad 2 "-O-\alpha-\mathrm{L}-$ rhamnosyl-6-C-fucosyl-3'-methoxyluteolin, 7,4'-dihidroxy -3'-methoxyflavone-2"-O- $\alpha$-L-rhamnosyl-6-C-fucoside, $2 "-O-\alpha$-L-rhamnosyl-6-C-3"-deoxyglucosyl-3'-methoxyluteolin, 6ax-5"'-methane-3'-methoxymaysin, ax-4"-OH3'-methoxymaysin and terpenoids, sterols, vitamins, minerals and polyphenolic acid ${ }^{5-9}$.

\section{*Corresponding author:}

*Fazilatun Nessa dr.fazilatun@dpc.edu, nessa1995@yahoo.com 
In-vivo pharmacological study on corn silk revealed that it has various health benefits effect such as antidiabetic ${ }^{10}$ reduction of hyperglycemia ${ }^{11-12}$, antifatigue activity ${ }^{13}$, anti-stress activity ${ }^{14}$, anti-depressant activity ${ }^{15}$, diuretic activity ${ }^{16}$ and diabetic nephropathy inhibitory activity ${ }^{17}$. In addition a number of researches also conducted on in-vitro study of corn silk as literature review revealed it has antioxidant activity ${ }^{2-4,18-19}$, antibacterial activity ${ }^{20-21}$, and anti-inflammatory activity ${ }^{22-23}$. Many of these alleged pharmacological activities are linked to their flavonoids and flavonoids glycosides contents. The health benefits of flavonoid and flavonoid rich extracts are widespread as they act as strong antioxidants, free radical scavengers, metal chelators, superoxide scavengers and xanthine oxidase inhibitors $^{24-25}$ and they are also to interact with enzymes and bio-membranes ${ }^{26}$.

The use of appropriate solvent for extraction of flavonoids from medicinal plants is also a very important factor as most of the flavonoids aglycone are less soluble in water ${ }^{27}$ whereas flavonoid glycosides are sparingly soluble in water due to their sugar contents. Since water is a common solvent for the preparation of corn silk tea extracts, therefore the aim of this work was to find out the health beneficial effects of water extracts by evaluating antioxidant and xanthine oxidase inhibitory activities in comparison with reference compounds. In addition, the aim also extended to optimize the boiling time and technique for preparation of water extracts and to find the correlation of antioxidant and XO inhibitory activities of extracts with their total polyphenolic and total flavonoids contents.

\section{MATERIALS AND METHODS}

\subsection{Chemicals}

2,2-diphenyl-1-picryl-hydrazyl $\left(\mathrm{DPPH}^{\bullet}\right), 2,2$ azinobis(3-ethylbenzothiozoline-6-sulfonic acid) disodium salt (ABTS), potassium persulfate, $( \pm$ )-6-Hydroxy2,5,7,8-tetramethylchromane-2-carboxylic acid (Trolox), Folin-Ciocalteau reagent, nitroblue tetrazolium (NBT), phenazine methosulfate (PMS), beta-nicotinamideadenine dinucleotide (beta-NADH), potassium phosphate monobasic, sodium phosphate dibasic, sodium carbonate, and xanthine oxidase (XO) from bovine milk (25 units x 2, lyophilized powder, $2.3 \mathrm{~g}$ solid, 10.7 units/ solid), allopurinol (AP), L-ascorbic acid (AA), xanthine $(\mathrm{X})$, quercetin $(\mathrm{QU})$, aluminum chloride, sodium nitrite, sodium hydroxide, rutin and analytical grade ethanol were all purchased from Merck or Sigma Aldrich. HPLC grade methanol was used for spectroscopic analysis. Milli-Q Ultrapure (Type 1) water was used for aqueous extraction and reagents preparation.

\subsection{Extraction procedure}

Commercially available raw unripe corn were purchased from several supermarkets of United Arab Emirates (Dubai, Sharjah and Abu Dhabi). The silks were separated by using hand from the corn and later dried in an oven at $40^{\circ} \mathrm{C}$ temperature until dried and grinded into fine powder and stored in air-tight container for further using. $1 \%$ to $5 \%(\mathrm{w} / \mathrm{v})$ corns silk extracts solution were prepared by heating the sample with water at hotplate for $30 \mathrm{~min}$ at $120^{\circ} \mathrm{C}$ and as well heated in microwave oven for $2 \mathrm{~min}(700 \mathrm{~W})$ respectively. Microwave heated water extracts were named as MWWCS and hotplate heated extracts as HP-WCS. The yield of extracts were recorded and expressed as $\mathrm{mg}$ solid/ml of extract solution.

\subsection{Total Polyphenol and total flavonoids contents determination}

Diluted Folin-Ciocalteau (FC) reagent (1:10) in water was used for determination of polyphenol contents of corn silk extracts ${ }^{28}$. Briefly, $2 \mathrm{ml}$ FC reagent was mixed with $100 \mu \mathrm{l}$ samples and standard solutions (three replicates) in the test tubes and then added $2 \mathrm{ml}$ of $7.5 \%$ sodium carbonate solution. Different concentration of quercetin solutions were used as a standard polyphenol. The test tubes were kept for $90 \mathrm{~min}$ at ambient temperature $\left(25^{\circ} \mathrm{C}\right)$ and the absorbance were then recorded at $760 \mathrm{~nm}$ using Shimadzu-1700 UV-VIS spectrophotometer (Japan) against a blank prepared without addition of sample. A calibration curve $\left(\mathrm{y}=0.0034 \mathrm{x}-0.0065 ; \mathrm{R}^{2}=0.9992\right)$ was prepared with different concentration $(1-100 \mu \mathrm{g} / \mathrm{ml})$ of quercetin solution and it was utilized for quantification of total polyphenol contents of the unknown. Total polyphenol contents were expressed as mg quercetin equivalent polyphenol present per ml of corn silk extract solution.

The total flavonoids contents of water extracts were also determined with aluminum chloride ${ }^{29}$. In this method, 5 different concentration of rutin (50 to 700 $\mu \mathrm{g} / \mathrm{ml})$ in water:methanol (80:20) were prepared and used for the preparation of a calibration curve. In a series of 10 volumetric flasks, $1 \mathrm{ml}$ of sample and standards were mixed with $300 \mu 1$ of sodium nitrite $(5 \%)$ and $4 \mathrm{ml}$ MilliQ water and kept the solutions for $5 \mathrm{~min}$. Then added $1 \mathrm{ml} 300 \mu \mathrm{l}$ of aluminum chloride (10\%) and stand for $1 \mathrm{~min}$ before addition of $2 \mathrm{ml}$ sodium hydroxide (1M) and made the volume up to $10 \mathrm{ml}$ with MilliQ water. The absorbance of the reddish color solution were then read at $510 \mathrm{~nm}$ spectrophotometrically against blank solution prepared in the sample manner except aluminum chloride instead $300 \mu \mathrm{l}$ MilliQ water were added. The results were calculated by utilizing the linear regression equation $\left(\mathrm{y}=0.0008 \mathrm{x}+0.0157 ; \mathrm{R}^{2}=0.9939\right)$ and expressed as mg rutin equivalent flavonoid (mean value of triplicate analysis) per $\mathrm{ml}$ of corn silk extract solution. 


\subsection{Evaluation of antioxidant and xanthine oxidase inhibitory activities}

\subsubsection{DPPH ${ }^{\bullet}$ radical scavenging activity evaluation}

The $\mathrm{DPPH}^{\bullet}$ radical scavenging activity of corn silk extract solution was determined using a slightly modified method of Nessa et al. ${ }^{28}$. In this procedure, at first the absorbance of freshly prepared $\mathrm{DPPH}^{\bullet}$ radical solution $(25 \mu \mathrm{g} / \mathrm{ml})$ in methanol was adjusted to $0.750 \pm 0.02$ at $517 \mathrm{~nm}$. For antioxidant determination, 3 $\mathrm{ml}$ of $\mathrm{DPPH}^{\bullet}$ solution was then mixed with $100 \mu \mathrm{l}$ corn silk extract solution and continuously recorded the changes in absorbance at $2 \mathrm{~min}$ intervals for $30 \mathrm{~min}$ at $517 \mathrm{~nm}$ against a blank with a spectrophotometer. The results were expressed as \% scavenging of $\mathrm{DPPH}^{\bullet}$ at 30 min intervals using the formula $=\left[\left\{\left(\mathrm{A}_{\mathrm{DPPH}}{ }^{\bullet}{ }_{\text {-Blank }}-\right.\right.\right.$ $\mathrm{A}_{\mathrm{DPPH}}{ }^{\bullet}$-antioxidant $\left.) / \mathrm{A}_{\mathrm{DPPH} \bullet-\mathrm{Blank}}\right\} \mathrm{x} 100 \mathrm{j}$ from a triplicate analysis. A blank was prepared without added samples in methanolic solution of $\mathrm{DPPH}^{\bullet}$. L-Ascorbic acid and quercetin were used as reference antioxidants.

\subsubsection{ABTS $^{\bullet+}$ radical cation scavenging activity evaluation}

A slightly modified method of Khampas et al. ${ }^{30}$ was used to generate $\mathrm{ABTS}^{\bullet+}$ for evaluation of free radical scavenging activities of corn silk extracts. $7 \mathrm{mM}$ ABTS solution and $2.5 \mathrm{mM}$ potassium persulphate solution were prepared in water and equal volume of both solution were mixed in an amber colored bottle and kept in dark for $16 \mathrm{hr}$ to generate $\mathrm{ABTS}^{\bullet+}$ radical cation. The $\mathrm{ABTS}^{\bullet+}$ solution was then diluted to ethanol to obtain absorbance 0.725 to 0.750 at $734 \mathrm{~nm}$. $2 \mathrm{ml}$ of ABTS $^{\bullet+}$ solution was mixed with $100 \mu$ of corn silk extracts solution and recorded the changes of absorbance continuously for 7 min against blank at $734 \mathrm{~nm}$. Trolox, L-ascorbic acid and quercetin were used as reference compounds. \% scavenging of $\mathrm{ABTS}^{\bullet+}$ were calculated from triplicates analysis using the formula as $=\left[\left\{\left(\mathrm{A}_{\mathrm{ABTS}}{ }^{\bullet+}{ }_{\text {-Blank }}-\mathrm{A}_{\mathrm{ABTS}}{ }^{\bullet+}{ }_{\text {-antioxidant }}\right) / \mathrm{A}_{\mathrm{ABTS}}{ }^{\bullet+}{ }_{\text {-Blank }}\right\} \mathrm{x}\right.$ 100]. In addition, different concentration of Trolox (50 $\mu \mathrm{M}$ to $1000 \mu \mathrm{M})$ solution were tested for their ABTS $^{\bullet+}$ scavenging activities and constructed a calibration curve. The equation $\mathrm{y}=0.0817 \mathrm{x}+20.578\left(\mathrm{R}^{2}=0.9895\right)$ was used for calculation of $\mu \mathrm{M}$ Trolox equivalent antioxidants present in $100 \mathrm{ml}$ of extract solution.

\subsubsection{Xanthine oxidase $(X O)$ inhibition determination}

XO inhibitory activities of corn silk extract solution was evaluated by mixing sample solution $(1 \mathrm{ml})$, buffer $(\mathrm{pH} 7.5 ; 1.9 \mathrm{ml}), 100 \mu \mathrm{M}$ xanthine $(1 \mathrm{ml})$ and 0.0428 units $/ \mathrm{mL}$ XO $(0.1 \mathrm{ml})$ respectively. The resulting solution was incubated for $10 \mathrm{~min}$ at ambient temperature $\left(25^{\circ} \mathrm{C}\right)$. The enzyme reaction was stopped by adding $1 \mathrm{~N} \mathrm{HCl}(1 \mathrm{ml})$ and measured the absorbance for the production of uric acid at $295 \mathrm{~nm}$ spectrophotometrically. The corresponding blank solution were prepared in the same manner without adding XO instead buffer solution were added. The percent inhibition of $\mathrm{XO}$ by the antioxidants were calculated from triplicates measurements using the formula as follows: $=\left[\left\{\left(A_{\text {Blank }}\right.\right.\right.$ $\left.\left.\left.\mathrm{A}_{\text {antioxidant }}\right) / \mathrm{A}_{\mathrm{Blank}}\right\} \times 100\right]^{28}$. Allopurinol, L-ascorbic acid and quercetin were used as reference compounds in this study.

\subsubsection{Superoxide radical scavenging activity evaluation}

In this study superoxide radical anion $\left(\mathrm{O}_{2}{ }^{\bullet-}\right)$ were generated both enzymatically and chemically ${ }^{28}$. Enzymatically superoxide radicals were generated using xanthine $(\mathrm{X})$ and $\mathrm{XO}$ reaction $(\mathrm{X} / \mathrm{XO})$. In enzymatic determination, the reaction mixture were comprised of $1 \mathrm{ml}$ corn silk extracts, $0.9 \mathrm{ml}$ buffer $\mathrm{pH} 7.5,100 \mu \mathrm{M} 1$ $\mathrm{ml}$ xanthine, $0.1 \mathrm{ml} \mathrm{XO}(0.0428$ units $/ \mathrm{ml})$ and $1 \mathrm{ml}$ NBT $(600 \mu \mathrm{M})$ respectively. The corresponding blank solutions were prepared without addition of XO. The reaction mixtures were then incubated at room temperature $\left(25^{\circ} \mathrm{C}\right)$ for $10 \mathrm{~min}$ and read the absorbance at $560 \mathrm{~nm}$. The extract solution were also tested against chemically generated $\mathrm{O}_{2}^{\bullet-}$ using PMS and $\mathrm{NADH}$ system in phosphate buffer at $\mathrm{pH}$ 7.5. In this technique, the reaction mixtures were comprised of $1 \mathrm{ml}$ corn silk extracts, $1.9 \mathrm{ml}$ buffer $\mathrm{pH}$ 7.5, $20 \mu \mathrm{M} 1 \mathrm{ml}$ PMS, $156 \mu \mathrm{M}$ $1 \mathrm{~mL} \mathrm{NADH}$ and $1 \mathrm{ml} \mathrm{NBT}(25 \mu \mathrm{M})$. The blanks were prepared with the same composition without adding PMS, instead buffer was added. All the samples were hold for $5 \mathrm{~min}$ at room temperature before read the absorbance at $560 \mathrm{~nm}$. The both experiments were repeated for three times and the results were expressed as $\%$ scavenging of superoxide radicals $=\left[\left\{\left(A_{B l a n k}-\right.\right.\right.$ $\left.\left.\left.\mathrm{A}_{\text {antioxidant }}\right) / \mathrm{A}_{\text {Blank }}\right\} \times 100\right]$.

\subsection{Statistical Analysis}

The analysis was conducted using IBM SPSS Statistics 23. All the results were expressed as mean \pm standard deviation (SD). The data of different solvent extracts and reference compounds were compared using a one-way analysis of variance (ANOVA). Tukey's test $(p<0.05)$ was performed to determine the significance of the difference in means of between groups and within groups.

\section{RESULTS}

\subsection{Total polyphenol and total flavonoids contents}

Water extracts of corn silk with variable sample sizes were used in this study and the extracts were 
divided into two categories based on the mode of preparation either with a hot-plate heating (HP-WCS) or microwave power heating (MW-WCS) procedure. The yield of extracts were expressed as $\mathrm{mg}$ solid/ $/ \mathrm{ml}$ extracts and were in the ranged of 0.05 to $2.09 \mathrm{mg} / \mathrm{ml}$. Amongst the water extracts $5 \% \mathrm{MW}$-WCS extract's solid contents was higher than corresponding HP-WCS extracts and the solid contents of water extracts are presented in Table 1. The quercetin equivalent total polyphenols (mg QU/ml extract solution) of water extracts are presented in Table 1 . Amongst $1 \%$ to 5\% HP-WCS and MW-WCS water extracts, quercetin equivalents total polyphenols contents were decreased in the order of: $5 \%>4 \%>3 \%$ $>2 \%>1 \%$. MW-WCS extracts contained comparatively higher concentration of total polyphenols (0.121 to $0.564 \mathrm{mg} / \mathrm{ml})$ than HP-WCS extracts $(0.113$ to 0.523 $\mathrm{mg} / \mathrm{ml}$ ). Rutin equivalents total flavonoid contents (mg $\mathrm{RU} / \mathrm{ml}$ extract solution) of both water extracts were also quantified and the results are presented in Table 2. Microwave heated water extracts contained higher level of total flavonoids $(0.073-0.326 \mathrm{mg} / \mathrm{ml})$ than hot-plated heated water extracts $(0.055-0.306 \mathrm{mg} / \mathrm{ml})$. Total Flavonoid contents of extract solution increased with increasing sample size within a fixed extraction period.

Table 1. Solid contents, polyphenols, Trolox equivalent antioxidants (TREA) contents and free radicals scavenging activities of different types of corn silk extracts solution as assessed with $\mathrm{DPPH}^{\bullet}$ and $\mathrm{ABTS}^{\bullet+}$ radical scavenging method. Results are mean $\pm \operatorname{SD}(n=3)$.

\begin{tabular}{|c|c|c|c|c|c|}
\hline $\begin{array}{l}\text { Types of Water } \\
\text { Extracts of Corn } \\
\text { silk powder } \\
\end{array}$ & $\begin{array}{c}\text { mg solid/ ml } \\
\text { Extract }\end{array}$ & $\begin{array}{c}\text { mg Eq. } \\
\text { Quercetin/ml Extract } \\
* \text { Mean } \pm \text { SD }(n=3)\end{array}$ & $\begin{array}{c}\% \text { DPPH }^{\bullet} \\
\text { Scavenging activity } \\
* \text { Mean } \pm \text { SD }(n=3) \\
\end{array}$ & $\begin{array}{c}\% \text { ABTS }^{\bullet+} \\
\text { Scavenging activity } \\
* \text { Mean } \pm \text { SD }(n=3) \\
\end{array}$ & $\begin{array}{c}\mu \text { TREA/ } 100 \mathrm{ml} \\
\text { Extract solution } \\
* \text { Mean } \pm \text { SD }(n=3) \\
\end{array}$ \\
\hline \multicolumn{6}{|c|}{ Hotplate Heated Water Extracts $\left(120^{\circ} \mathrm{C}\right.$ for $\left.30 \mathrm{~min}\right)$} \\
\hline $1 \%$ HP-WCS & 0.40 & $0.113 \pm 0.006$ & a29.55 291.01 & $31.18 \pm 0.54$ & $129.84 \pm 6.68$ \\
\hline $2 \%$ HP-WCS & 0.92 & $0.223 \pm 0.015$ & b43.73 \pm 1.52 & a $51.82 \pm 0.65$ & $382.39 \pm 7.95$ \\
\hline $3 \% \mathrm{HP}-\mathrm{WCS}$ & 1.42 & $0.321 \pm 0.009$ & $54.46 \pm 0.72$ & b $60.57 \pm 1.00$ & $489.49 \pm 12.24$ \\
\hline $4 \% \mathrm{HP}-\mathrm{WCS}$ & 1.83 & $0.410 \pm 0.011$ & ${ }^{\mathrm{c}} 66.57 \pm 1.31$ & $74.85 \pm 1.12$ & $664.36 \pm 13.76$ \\
\hline $5 \%$ HP-WCS & 2.01 & $0.523 \pm 0.007$ & $\mathrm{~d} 73.79 \pm 1.02$ & $89.22 \pm 0.57$ & $840.17 \pm 6.99$ \\
\hline \multicolumn{6}{|c|}{ Microwave Heated Water Extracts (2 min, 700 W) } \\
\hline $1 \% \mathrm{MW}-\mathrm{WCS}$ & 0.44 & $0.121 \pm 0.004$ & a $30.59 \pm 2.00$ & $38.15 \pm 0.52$ & $215.07 \pm 6.41$ \\
\hline $2 \% \mathrm{MW}-\mathrm{WCS}$ & 1.09 & $0.221 \pm 0.003$ & e $57.79 \pm 0.67$ & b57.71 \pm 0.78 & $454.49 \pm 9.61$ \\
\hline $3 \% \mathrm{MW}-\mathrm{WCS}$ & 1.54 & $0.356 \pm 0.006$ & ${ }^{\mathrm{c}} 67.44 \pm 2.00$ & ${ }^{\mathrm{c}} 64.84 \pm 0.62$ & $541.80 \pm 7.65$ \\
\hline $4 \% \mathrm{MW}-\mathrm{WCS}$ & 1.93 & $0.497 \pm 0.012$ & $\mathrm{~d} 75.83 \pm 2.05$ & $82.56 \pm 0.99$ & $758.69 \pm 12.17$ \\
\hline $5 \% \mathrm{MW}-\mathrm{WCS}$ & 2.09 & $0.564 \pm 0.022$ & $85.08 \pm 0.79$ & $98.11 \pm 1.72$ & $953.02 \pm 14.49$ \\
\hline \multicolumn{6}{|c|}{ Reference Compounds } \\
\hline \multirow{2}{*}{\multicolumn{3}{|c|}{$\begin{array}{l}\text { Quercetin (QU) } 100 \mu \mathrm{M} \\
\text { L-Ascorbic Acid (AA) } 100 \mu \mathrm{M}\end{array}$}} & $\mathrm{e} 58.19 \pm 1.37$ & ${ }^{\mathrm{c}} 64.50 \pm 0.47$ & \\
\hline & & & b45.40 \pm 0.53 & ${ }^{\mathrm{a}} 51.52 \pm 0.52$ & \\
\hline
\end{tabular}

*Mean with superscript similar small alphabet (a,b,c, etc.) within the column were not significantly different $(p<0.05)$.

Table 2. Rutin equivalent flavonoids contents and percent inhibition of xanthine oxidase (XO) and scavenging of superoxide radicals (produced enzymatically and non-enzymatically) by two different types of corn silk water extracts solution. Results are mean \pm SD $(n=3)$.

\begin{tabular}{|c|c|c|c|c|}
\hline $\begin{array}{l}\text { Types of Water } \\
\text { Extracts of Corn } \\
\text { silk powder } \\
\end{array}$ & $\begin{array}{c}\text { mg Eq. } \\
\text { Rutin/ml Extract } \\
* \text { Mean } \pm \text { SD }(n=3) \\
\end{array}$ & $\begin{array}{l}\text { \% Inhibition of XO } \\
* \text { Mean } \pm \text { SD }(n=3)\end{array}$ & $\begin{array}{c}\text { \% Scavenging of Superoxide } \\
\text { radicals }(\text { Enzymatic) } \\
\text { *Mean } \pm \text { SD }(n=3)\end{array}$ & $\begin{array}{c}\text { \% Scavenging of Superoxide } \\
\text { radicals (Non-Enzymatic) } \\
* \text { Mean } \pm \operatorname{SD}(n=3)\end{array}$ \\
\hline \multicolumn{5}{|c|}{ Hotplate Heated Water Extracts $\left(120^{\circ} \mathrm{C}\right.$ for $\left.30 \mathrm{~min}\right)$} \\
\hline $1 \%$ HP-WCS & $0.055 \pm 0.006$ & $11.87 \pm 0.80$ & $26.40 \pm 0.55$ & $22.40 \pm 1.84$ \\
\hline $2 \%$ HP-WCS & $0.155 \pm 0.011$ & $22.33 \pm 0.85$ & $37.47 \pm 0.61$ & $32.81 \pm 0.98$ \\
\hline $3 \%$ HP-WCS & $0.202 \pm 0.002$ & $40.37 \pm 0.48$ & $49.78 \pm 0.79$ & $42.45 \pm 1.16$ \\
\hline 4\% HP-WCS & $0.265 \pm 0.021$ & $51.03 \pm 0.42$ & a $58.75 \pm 0.95$ & $52.74 \pm 1.05$ \\
\hline $5 \%$ HP-WCS & $0.306 \pm 0.009$ & $74.17 \pm 1.32$ & $78.68 \pm 1.07$ & $70.35 \pm 1.15$ \\
\hline \multicolumn{5}{|c|}{ Microwave Heated Water Extracts (2 min, 700 W) } \\
\hline $1 \% \mathrm{MW}-\mathrm{WCS}$ & $0.073 \pm 0.011$ & $15.13 \pm 0.97$ & $29.83 \pm 0.87$ & $25.49 \pm 0.28$ \\
\hline $2 \% \mathrm{MW}-\mathrm{WCS}$ & $0.171 \pm 0.008$ & $33.96 \pm 0.55$ & $41.24 \pm 1.15$ & $37.91 \pm 0.51$ \\
\hline $3 \% \mathrm{MW}-\mathrm{WCS}$ & $0.219 \pm 0.010$ & $45.64 \pm 0.81$ & $52.25 \pm 0.50$ & $48.58 \pm 1.31$ \\
\hline 4\% MW-WCS & $0.271 \pm 0.009$ & $60.44 \pm 0.76$ & $66.61 \pm 0.66$ & $59.38 \pm 1.05$ \\
\hline $5 \% \mathrm{MW}-\mathrm{WCS}$ & $0.326 \pm 0.007$ & $80.59 \pm 1.02$ & $86.35 \pm 1.01$ & $79.53 \pm 1.48$ \\
\hline \multicolumn{5}{|c|}{ Reference Compounds } \\
\hline \multicolumn{2}{|c|}{ Quercetin $(100 \mu \mathrm{M})$} & $82.61 \pm 1.02$ & $94.08 \pm 0.83$ & $91.74 \pm 1.11$ \\
\hline \multicolumn{2}{|c|}{ L-Ascorbic Acid $(100 \mu \mathrm{M})$} & $28.59 \pm 0.63$ & a58.66 \pm 0.67 & \\
\hline \multicolumn{2}{|c|}{ Allopurinol $(5 \mu \mathrm{M})$} & $71.28 \pm 0.54$ & $81.63 \pm 0.65$ & \\
\hline
\end{tabular}

* Mean with similar small alphabet (a) within the column were not significantly different $(p<0.05)$. 


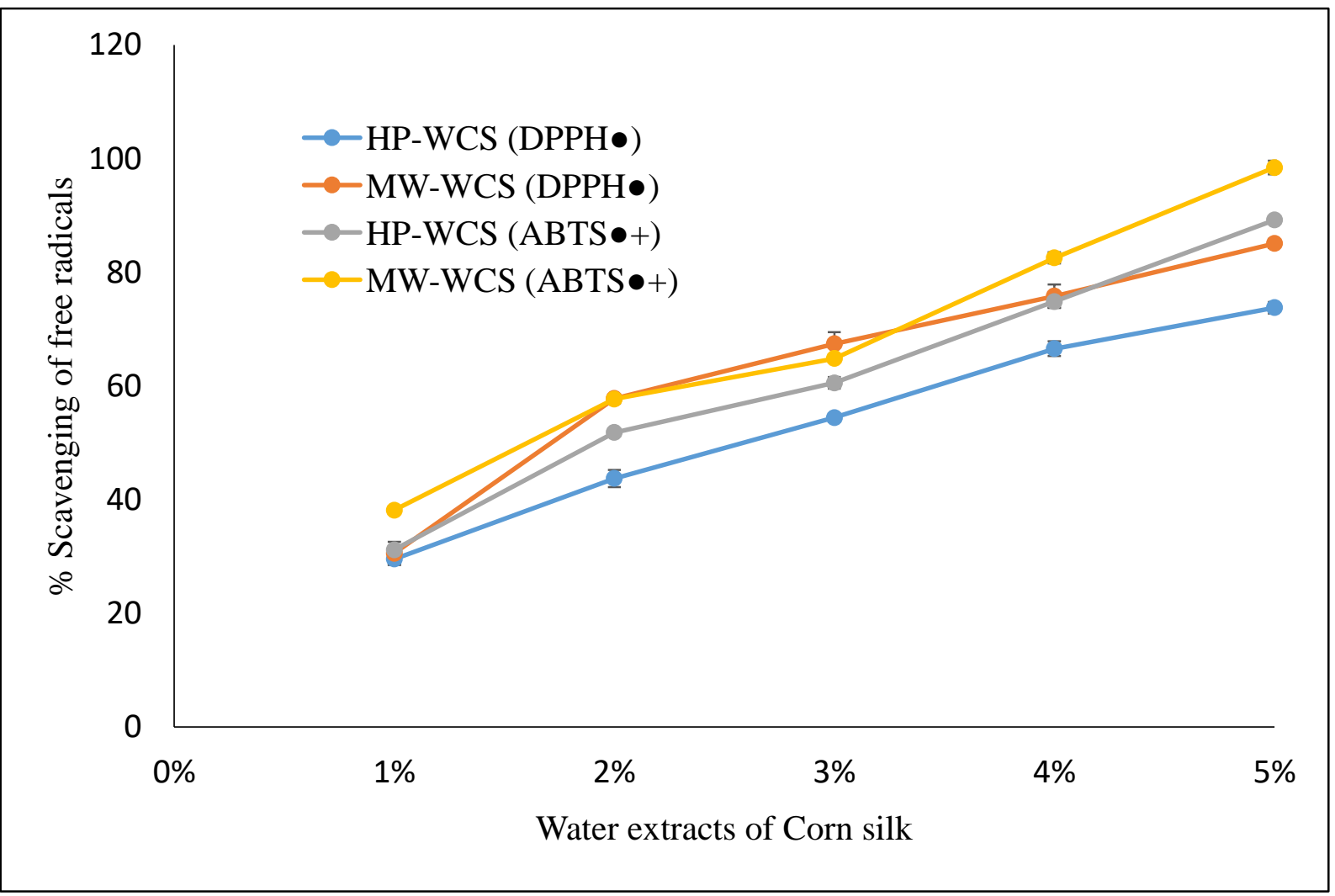

Figure 1. Free radicals scavenging activities of hotplate (HP-WCS) and microwave heated water extracts (MW-WCS) of corn silk measured using the $\mathrm{DPPH}^{\bullet}$ and $\mathrm{ABTS}^{\bullet+}$ assay. Results are mean $\pm \mathrm{SD}(n=3)$.

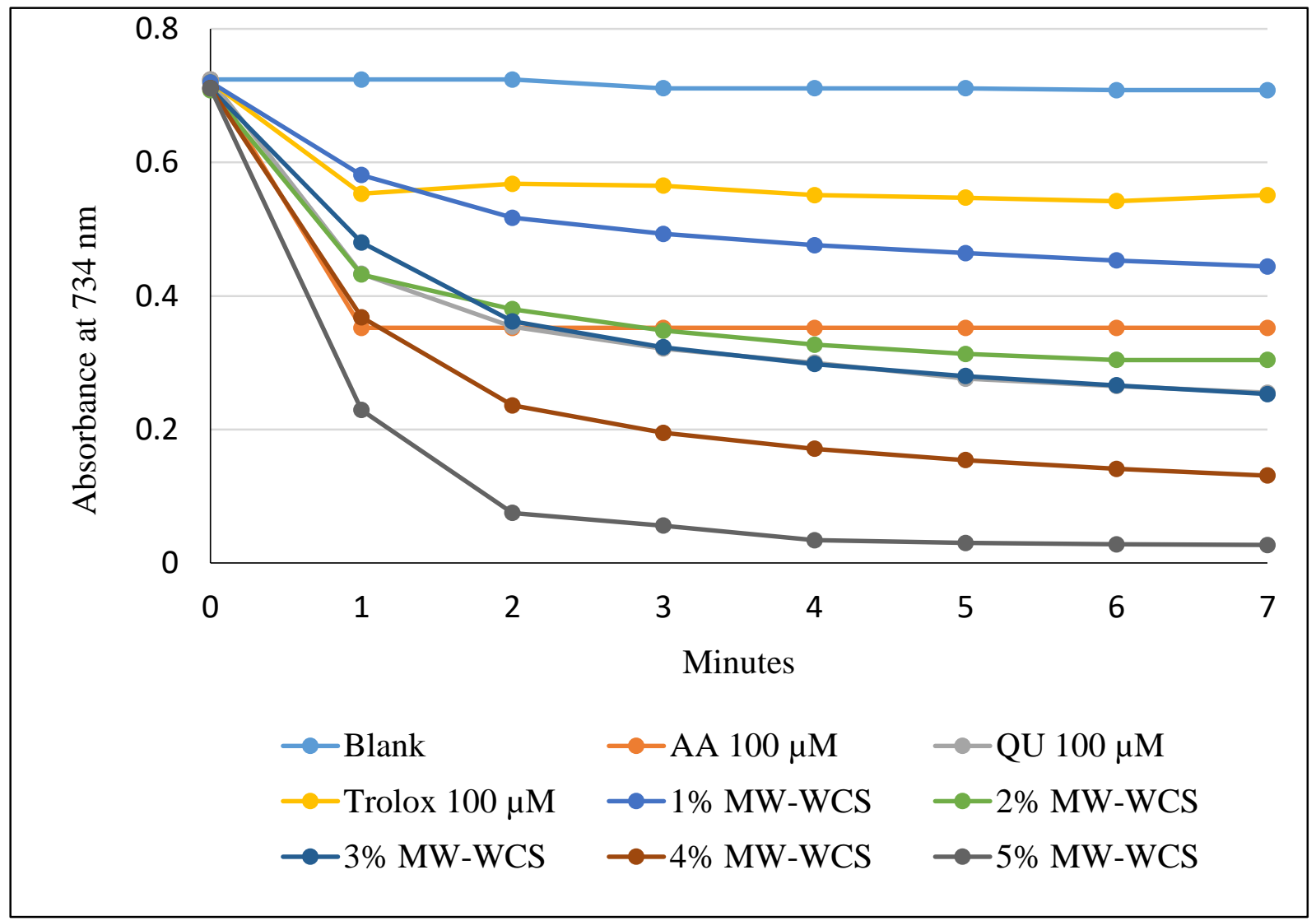

Figure 2. Hydrogen donating abilities of $1 \%$ to $5 \%$ microwave heated corn silk water extracts (MW-WCS) and reference compounds on $\mathrm{ABTS}^{\bullet+}$. Quercetin (QU), L-ascorbic acid (AA) and Trolox were used as reference compounds. 
Hence, $5 \%$ extracts contained higher level of total flavonoids than their corresponding $1 \%$ extracts.

\section{2. $\mathrm{DPPH}^{\bullet}$ radical scavenging activity}

The DPPH ${ }^{\bullet}$ scavenging activities of corn silk extracts were expressed in percent (\%) and amongst the water extracts MW-WCS showed comparatively slightly higher $\mathrm{DPPH}^{\bullet}$ reduction capability than HP-WCS extracts. Amongst the MW-WCS extracts the lowest activity observed in $1 \%$ extract $(30.59 \%)$ and activity increased with increasing the concentration of corn silk powder and highest activity observed in 5\% extract $(85.08 \%)$ and the similar fashion was also observed for HP-WCS extracts. The overall results of $\mathrm{DPPH}^{\bullet}$ scavenging activity of water extracts were increased in the order of: $1 \%<2 \%<3 \%<4 \%<5 \%$. The results were compared statistically between MW-WCS and HP-WCS. There were a statistical significant differences $(p<0.05)$ in activity observed within groups, however, in between groups, there were no statistical significant differences observed of $1 \%$ HP-WCS with $1 \%$ MW-WCS, $4 \%$ HPWCS with 3\% MW-WCS and 5\% HP-WCS with $4 \%$ MW-WCS extracts respectively. In comparison with reference compounds as quercetin $(\mathrm{QU})$ and L-ascorbic acid (AA), water extracts (4\%-5\%) were significantly higher in $\mathrm{DPPH}^{\bullet}$ scavenging activity than $100 \mu \mathrm{M}$ of QU and AA respectively. However, there were no statistically significant differences $(p<0.05)$ in between $2 \%$ MW-WCS and QU; and 2\% HP-WCS and AA respectively. A linear curve was constructed using $\%$ reduction of $\mathrm{DPPH}^{\bullet}$ versus $1 \%$ to $5 \%$ HP-WCS and MW-WCS extracts and $\mathrm{IC}_{50}$ values were calculated using the equation $y=1270.2 x+25.246\left(R^{2}=0.9225\right)$ for MW-WCS and the equation $y=1113.1 x+20.23\left(R^{2}=0.9895\right)$ for HPWCS respectively as shown in Figure 1 . The $\mathrm{IC}_{50}$ value of HP-WCS was $2.67 \%$ slightly higher than that of MW-WCS (1.95\%) extracts.

\section{3. $\mathrm{ABTS}^{\bullet+}$ Radical cation scavenging activity}

In laboratory generated $\mathrm{ABTS}^{\bullet+}$ were used to evaluate the free radical scavenging activities of corn silk extracts. The results were expressed in percent (\%) scavenging of radicals. Hotplate heated 1\% HP-WCS extracts was able to reduce $31.18 \% \mathrm{ABTS}^{\bullet+}$ and activity increasing with increasing the concentration of corn silk power as of $5 \%>4 \%>3 \%>2 \%>1 \%$. The results are shown in Table 1. In case of microwave heated water extracts, similar fashion was also observed as higher activity recorded in 5\% MW-WCS (98.11\%) than 1\% MW-WCS (38.15\%) (Table 1). In comparison with reference compounds as L-ascorbic acid (AA) and quercetin $(\mathrm{QU})$, there were no statistically significant differences $(p<0.05)$ in between 2\% HP-WCS and AA. The absorbance at $734 \mathrm{~nm}$ vs. time response curve for
MW-WCS is presented in Figure 2 and it was depicted that $\mathrm{AA}$ reacted with $\mathrm{ABTS}^{\bullet+}$ and stabilized the reaction very fast within $1 \mathrm{~min}$ whereas the extract solution, 100 $\mu \mathrm{M}$ Trolox, QU became steady at 5 to 7 min (Figure 2). In comparison between two types of water extracts, microwave heated extracts were more potent in reduction of $\mathrm{ABTS}^{\bullet+}$ from experimental solution than hotplate heated extracts as of their higher total polyphenols and total flavonoids contents. The $\mathrm{IC}_{50}$ values were also calculated from a regression line (Figure 1) constructed with $1 \%$ to $5 \%$ extracts solution vs. scavenging of $\mathrm{ABTS}^{\bullet+}$, where the equation $\mathrm{y}=1391 \mathrm{x}+19.8\left(\mathrm{R}^{2}=0.9871\right)$ was used for HP-WCS and $y=1454.3 x+24.711\left(R^{2}=0.9861\right)$ for MW-WCS extracts solution respectively. The recorded $\mathrm{IC}_{50}$ value was $1.74 \%$ for MW-WCS slightly lower than corresponding HP-WCS extracts $(2.17 \%)$. The Trolox equivalent antioxidants $(\mu \mathrm{M}$ TREA) present in $100 \mathrm{~mL}$ extract solution were also calculated from the linear regression line. The recorded $\mu \mathrm{M}$ TREA in $1 \%$ to $5 \%$ HP-WCS extracts were in the ranges of $129.84-840.17 \mu \mathrm{M}$ and 215.07-953.02 $\mu \mathrm{M}$ in MW-WCS extracts respectively. As per ranking of potent antioxidants, 5\% water extracts solution efficiently scavenged $\mathrm{ABTS}^{\bullet+}$ rather than $1 \%$ extract solution and MW-WCS was more potent than HP-WCS extracts. In comparison amongst the water extracts (1\%-5\%), all were statistically significantly $(p<0.05)$ different from each other. The results of $\mu \mathrm{M}$ TEQA contents of the extracts are presented in Table 1.

\subsection{Xanthine oxidase (XO) inhibitory activities}

Ten corn silk water extracts solution and three reference standards were tested for their in-vitro XO inhibitory activities. Amongst the two types of water extracts, hot-plate heated water extract HP-WCS showed slightly lower activity (11.87\% to $74.17 \%)$ than their corresponding microwave heated water extract MW-WCS (15.13\% to $80.59 \%$ ) in reduction of uric acid production. The overall ranking for the both types of water extracts in response to inhibition of $\mathrm{XO}$ were decreased in the order of: $5 \%>4 \%>3 \%>2 \%>1 \%$. The results were compared with a potent $\mathrm{XO}$ inhibitorallopurinol (AP) and two natural antioxidants as Lascorbic acid (AA) and quercetin (QU). QU $(100 \mu \mathrm{M})$ and AP $(5 \mu \mathrm{M})$ were highly effective in reduction of uric acid production whereas AA $(100 \mu \mathrm{M})$ was not. However, $3 \%$ to $5 \%$ MW-WCS water extracts solution showed higher XO inhibitory activities than AA and the overall ranking of the water extracts were increased in the order of: $\mathrm{QU}>5 \%>\mathrm{AP}>4 \%>3 \%>2 \%>1 \%$. Statistically the results were significantly differences $(p<0.05)$ in activity in between groups and within groups of HP-WCS and MW-WCS. $\mathrm{IC}_{50}$ values were calculated from a regression lines based on the results 
obtained from $1 \%-5 \%$ water extracts as shown in Figure 3. The equation $y=1532.8 x-6.029\left(R^{2}=0.9821\right)$ for HP-WCS and $\mathrm{y}=1573.9 \mathrm{x}-0.0653\left(\mathrm{R}^{2}=0.9924\right)$ for MWWCS were used for calculation of 50\% reduction of production of uric acid and it was observed that the calculated $\mathrm{IC}_{50}$ value was lower for MW-WCS (3.18\%) than their corresponding HP-WCS (3.66\%) extracts.

\subsection{Superoxide radical anions $\left(\mathrm{O}_{2}{ }^{\bullet-}\right)$ scavenging activity}

Water extracts of corn silk extracts solution and reference compounds were tested against reduction of superoxide radicals produced enzymatically in a xanthine-xanthine oxidase (X/XO), or produced chemically in a non-enzymatic (PMS/NADH) system. NBT-a yellow color solution frequently used to detect the presence of $\mathrm{O}_{2}{ }^{\circ}$ that reduces NBT to purplish-blue diformazon. In presence of $\mathrm{O}_{2}{ }^{\circ-}$ scavengers less diformazon will be produced and it can measure the decrease in absorbance at $560 \mathrm{~nm}$ spectrophotometrically. Amongst the five different sample sizes of two different types of water extracts $1 \%$ to $5 \%$ microwave heated extracts (MW-WCS) were comparatively more active $\mathrm{O}_{2}{ }^{\circ-}$ scavengers than hot-plate heated extracts (HP-WCS). As $1 \%$ MW-WCS and 1\% HP-WCS exhibited $29.83 \%$ and $26.4 \%$ in reduction of $\mathrm{O}_{2}{ }^{-}$from the experimental solution. The concentration of corn silk extracts increasing from $1 \%$ to $5 \%$, the scavenging activity of $\mathrm{O}_{2}{ }^{-*}$ also increased as $5 \%$ HP-WCS and 5\% MW-WCS extract solution were able to scavenge superoxide radicals $78.68 \%$ and $86.35 \%$ respectively. The overall ranking for the both water extracts in scavenging of $\mathrm{O}_{2}{ }^{-}$were decreased in the order of: $5 \%>4 \%>3 \%>2 \%>1 \%$. In comparison with reference compounds quercetin (QU), L-ascorbic acid (AA) and allopurinol (AP), the revised order of activity of MW-WCS extracts were: $\mathrm{QU}>5 \%>\mathrm{AP}>4 \%>\mathrm{AA}$ $>3 \%>2 \%>1 \%$. QU $(100 \mu \mathrm{M})$ was more potent to scavenge of $\mathrm{O}_{2}{ }^{\bullet-}$ produced enzymatically than $5 \mu \mathrm{M}$ AP. AA was moderately active in reduction of $\mathrm{O}_{2}{ }^{\circ}$ in comparison with $4-5 \%$ corn silk water extracts. However, there was no statistically significant $(p<0.5)$ differences in activity in between 4\% HP-WCS and AA. The calculated $\mathrm{IC}_{50}$ values from the data of $1 \%-5 \%$ of HPWCS and MW-WCS extracts as presented in Figure 3 for scavenging of enzymatically produced $\mathrm{O}_{2}{ }^{--}$were $2.98 \%$ and $2.62 \%$ respectively. The equation $y=1258.4 x+$ $12.465\left(\mathrm{R}^{2}=0.9818\right)$ for HP-WCS and $\mathrm{y}=1384.1 \mathrm{x}+13.732$ $\left(\mathrm{R}^{2}=0.9836\right)$ for MW-WCS (Figure 3 ) were used for $\mathrm{IC}_{50}$ calculation.

In scavenging of non-enzymatically (PMS/ $\mathrm{NADH}$ ) produced $\mathrm{O}_{2}{ }^{\bullet}$, MW-WCS efficiently scavenged $\mathrm{O}_{2}{ }^{--}$than their corresponding HP-WCS. However, the similar fashion was also observed amongst the $1 \%$ to $5 \%$ water extracts in reduction of $\mathrm{O}_{2}{ }^{\circ-}$ from the experimental solution and the order of activity was decreased as follows: $5 \%>4 \%>3 \%>2 \%>1 \%$. In comparatively, corn silk water extracts were highly efficient in scavenging of enzymatically produced $\mathrm{O}_{2}{ }^{-*}$ rather than chemically produced $\mathrm{O}_{2}{ }^{-}$as $5 \%$ HP-WCS scavenged $78.68 \% \mathrm{O}_{2}{ }^{\circ}$ produced in $\mathrm{X} / \mathrm{XO}$ system and $70.35 \% \mathrm{O}_{2}{ }^{\circ}$ produced in PMS/NADH system. In this study a potent natural antioxidant QU was used as a reference compound and it showed highest activity than the studied extracts. The $\mathrm{IC}_{50}$ values of $1 \%$ to $5 \%$ water extracts (Figure 3) for scavenging of chemically produced $\mathrm{O}_{2}{ }^{\circ}$ were calculated using equations $y=1158.4 x+9.3987$ $\left(\mathrm{R}^{2}=0.983\right)$ and $\mathrm{y}=1295.4 \mathrm{x}+11.317\left(\mathrm{R}^{2}=0.9822\right)$ for HPWCS and MW-WCS respectively. The $\mathrm{IC}_{50}$ value for MW-WCS was $2.98 \%$ slightly lower than their corresponding HP-WCS extract solution (3.50\%).

\section{DISCUSSION}

Steeping of corn silk powder in hot water as the preparation of tea for few minutes or microwave heating for $1 \mathrm{~min}$ was not enough to extract complete bioactive compounds until boiling the solution for certain period of time that yielded deep brown colored solution. Hence, corn silk water extract solution as tea in concentration of $1 \%$ to $5 \%$ was prepared by either boiling the solution in microwave heat for 2 mins or in hot plate at $120^{\circ} \mathrm{C}$ for $30 \mathrm{~min}$. Microwave heated extract contained higher level of solid contents than their corresponding hotplate heated extracts. Amount of corn silk powder increasing from $1 \%$ to $5 \%$, total polyphenols and total flavonoids contents as well increased.

Corn silk contained a number of flavone-cglycosides, aglycones, vitamins and minerals ${ }^{4-8,}$ 19-21 Biological activities of corn silk are mainly related to their flavonoid glycosides contents. Most of the flavonoids and flavonoids glycosides are sparingly soluble in water, however in this study corn silk water extract were prepared by boiling the solution using either microwave heating or hotplate. The phytoconstituents of MW-WCS and HP-WCS extracts were quantified by using Folin-Ciocalteau reagent specific for estimation of total polyphenolic contents (Table 1). In addition total flavonoid contents of water extracts were also determined by reacting with aluminum chloride (Table 2). The results from both methods revealed that MW-WCS and HP-WCS extracts contained quercetin and rutin equivalent compounds.

Two free radicals as $\mathrm{DPPH}^{\bullet}$ and $\mathrm{ABTS}^{\bullet+}$ were used to evaluate antioxidant capacity of MW-WCS and HP-WCS extracts. A number of researchers reported on the organic extracts of corn silk against scavenging of $\mathrm{DPPH}^{\bullet 2,31}$ and in addition less information are available on the antioxidant study of corn silk water extracts. In this study the scavenging of both $\mathrm{DPPH}^{\bullet}$ and $\mathrm{ABTS}^{\bullet+}$ 
radicals, MW-WCS extracts exhibited higher free radical scavenging activity than HP-WCS due to their higher total flavonoids and polyphenols contents. In addition, 5\% corn silk tea/extract exhibited higher potency in scavenging of free radicals than their corresponding $1 \%$ extract irrespective of free radicals used as 5\% extracts contained highest level of total polyphenols and flavonoids. The antioxidant activity of flavonoid rich extracts are related to their hydrogen donating ability from their phenolic hydroxyl group of polyphenols or flavonoids and produces a stable end product stopped further propagation of chain reaction that credits to stop lipid peroxidation in biological system $^{32}$. The correlation between total polyphenols and total flavonoids contents of corn silk extracts (1\% to $5 \%$ ) with their $\mathrm{DPPH}^{\bullet}$ scavenging activities were established. The regression coefficients $\left(\mathrm{R}^{2}\right)$ in between total polyphenols/ $\mathrm{DPPH}^{\bullet}$ scavenging activities were 0.9868 for HP-WCS and 0.9087 for MW-WCS extracts. In between total flavonoid/DPPH ${ }^{\bullet}$ scavenging activities, the $\mathrm{R}^{2}$ values were 0.9933 and 0.9810 for HP-WCS and MW-WCS respectively. The correlation between scavenging of $\mathrm{ABTS}^{\bullet+}$ radicals and total flavonoids/ polyphenols were also linear and the $\mathrm{R}^{2}$ values were 0.9894 and 0.9906 for HP-WCS as well 0.9800 and 0.9643 for MW-WCS respectively as shown in Table 3. The $\mathrm{R}^{2}$ values revealed that there were a very good correlation between the free radical scavenging activity corn silk water extracts with their total polyphenols and flavonoids contents. In respect of Trolox equivalent antioxidants (TREA) estimation, 5\% MW-WCS contained higher TREA than their corresponding $1 \%$ extracts as $1 \%$ water extracts contained lower concentration of total polyphenols and flavonoids. The calculated $\mathrm{IC}_{50}$ values based on Figure 4 revealed that $1.74 \%$ and $1.95 \%$ MW-WCS extracts were capable in 50\% reduction of $\mathrm{ABTS}^{\bullet+}$ and $\mathrm{DPPH}^{\bullet}$ respectively, whereas $2.17 \%$ and $2.67 \%$ HP-WCS extracts were needed in reduction of $\mathrm{ABTS}^{\bullet+}$ and $\mathrm{DPPH}^{\bullet}$ radicals.

It is well documented that flavonoids and flavonoid glycosides can inhibit XO - an enzyme that produces uric acid and superoxide radicals $\left(\mathrm{O}_{2}{ }^{\bullet-}\right)^{33-34}$. As regards to the inhibition of XO by corn silk extracts, both water extracts (MW-WCS and HP-WCS) exhibited promising results in reduction of uric acid and superoxide radical production. This inhibitory activity increases with the increasing of extract concentration as 5\% extracts showed highest level of XO inhibitory activity than their corresponding $1 \%$ to $4 \%$ extracts. The linear correlation of $\mathrm{XO}$ inhibitory activities of water extracts with their total polyphenols and flavonoids contents were plotted and $\mathrm{R}^{2}$ values were in the ranged of 0.9223 to 0.9844 respectively as shown in Table 3 . From the $\mathrm{R}^{2}$ values it was evident that there were a good linear relationship in between XO inhibitory activities of corn silk water extracts with their total flavonoids contents. Hotplate heating system extracted comparatively slightly lower level of total flavonoids and polyphenol compounds in comparison with microwave heated extracts, resultant MW-WCS (1\% - 5\%) extracts solution were the most potent antioxidants for inhibition of XO and reduction the level of $\mathrm{O}_{2}{ }^{-}$than HPWCS (1\%-5\%). The mechanism of XO inhibition by flavonoids or flavonoids glycosides rich corn silk extracts was not clearly understood, and it has been known so far that the extent of XO inhibition mostly related to the substitution pattern of hydroxyl groups in the parent flavonoid compounds. A number of authors classified the mechanism of XO inhibition by flavonoid could be either a mixed type mode or competitive mode inhibition $^{35-36}$. The active components of MW-WCS and HP-WCS, which are responsible for this effect on enzyme, remain to be elucidated. In comparison between $\mathrm{IC}_{50}$ values of MW-WCS (3.18\%) and HPWCS $(3.65 \%)$ for XO inhibition, MW-WCS was more potent in reduction of in-vitro uric acid production. Similar fashion was also observed in scavenging of superoxide radical anion $\left(\mathrm{O}_{2}{ }^{\circ}\right)$ produced enzymatically (X/XO system) and chemically (PMS/NADH system). Based on the $\mathrm{IC}_{50}$ values, lower sample size was necessary against scavenging of superoxide radicals produced enzymatically rather than chemically. An average of $2.8 \%$ MW-WCS and 3.2\% HP-WCS extracts were enough in scavenging of $50 \%$ superoxide radicals. A linear correlation was also observed on the reduction of $\mathrm{O}_{2}{ }^{--}$with the reaction of corn silk water extracts. The sample size of extraction increases from $1 \%$ to $5 \%$ the total polyphenol $(0.113 \mathrm{mg} / \mathrm{ml}$ to $0.564 \mathrm{mg} / \mathrm{ml})$ and flavonoid $(0.055 \mathrm{mg} / \mathrm{ml}$ to $0.326 \mathrm{mg} / \mathrm{ml})$ contents also increased as well as scavenging of $\mathrm{O}_{2}{ }^{\circ-}$. It is also well documented that flavonoids act as superoxide radical anion scavengers due to the presence of phenolic hydroxyl group in the molecule ${ }^{34}$. The $\mathrm{R}^{2}$ values were 0.9326 to 0.9864 in response to correlation between total polyphenols and flavonoids contents of water extracts with the scavenging of chemically produced superoxide radicals. In a similar way, the $\mathrm{R}^{2}$ values were 0.9307 to 0.9866 in response to correlation between scavenging of enzymatically produced superoxide radicals of water extracts and their total flavonoids contents. The results of this study indicated that water extracts of corn silk were a good source of antioxidants as well as XO inhibitors. In comparison between two ways of prepared corn silk water extracts, it were revealed that health beneficial properties of corn silk can be achieved from tea/extracts prepared using microwave power heating for $2 \mathrm{~min}$ rather than longer boiling time for $30 \mathrm{~min}$ at $120^{\circ} \mathrm{C}$

\section{CONCLUSIONS}

Micro-wave heated water extracts of corn silk 


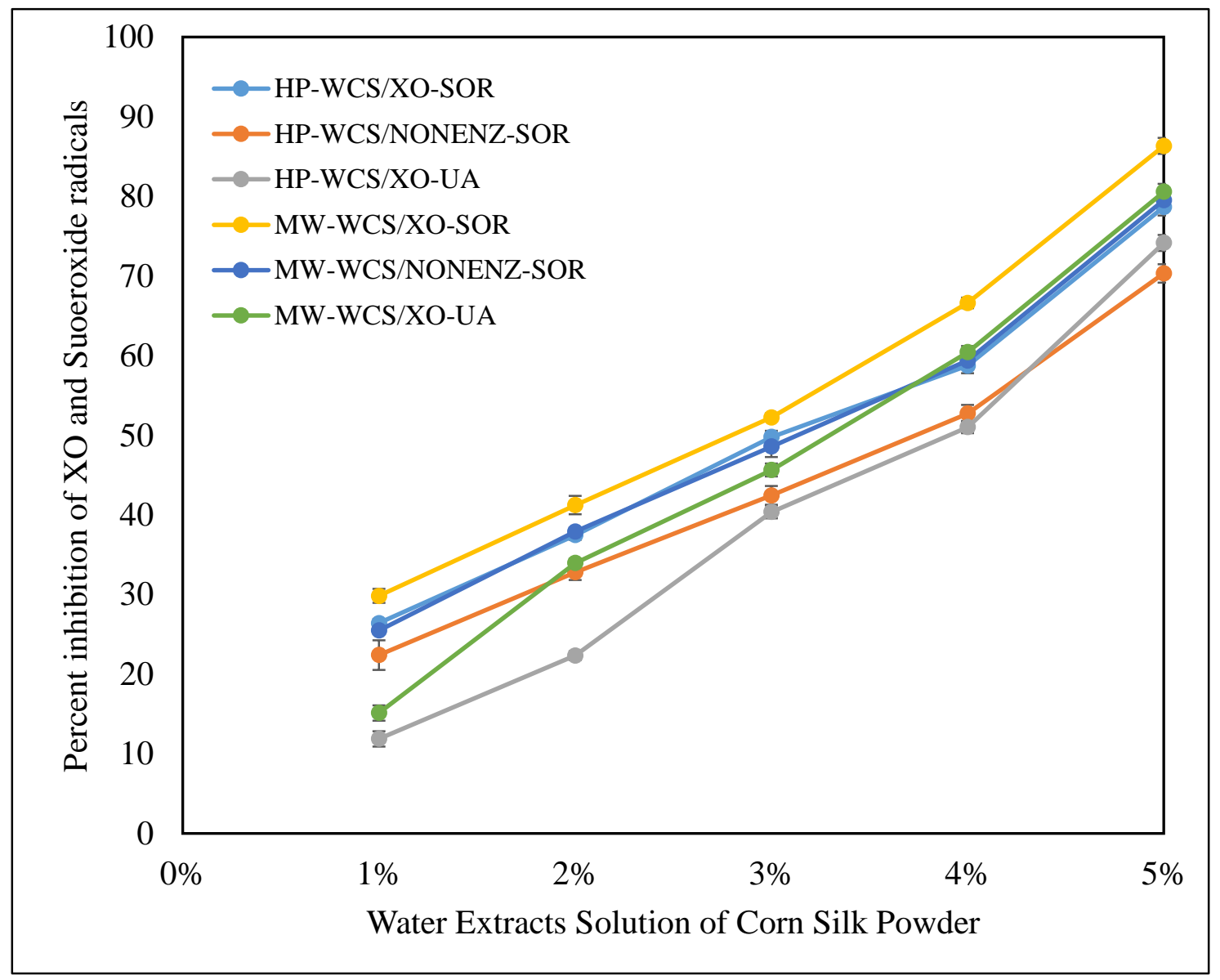

Figure 3. Hotplate (HP-WCS) and microwave (MW-WCS) heated water extracts of corn silk powder $v s$. the inhibition of xanthine oxidase (XO) and scavenging of superoxide radicals produced by enzymatically and non-enzymatically. Results are mean \pm SD ( $n=3$ ). [Legend: XOSOR = Scavenging of superoxide radicals produced by X/XO system; NON-ENZ-SOR = Scavenging of superoxide radicals produced by PMS/NADH system; XO-UA = inhibition of XO that produces uric acid and superoxide radicals.]

Table 3: Correlation of Total Polyphenols and Total Flavonoids contents of corn silk water extracts with their antioxidant and xanthine oxidase inhibitory activities.

\begin{tabular}{|c|c|c|c|c|c|c|}
\hline & \multicolumn{6}{|c|}{ Correlation coefficients $\left(\mathbf{R}^{2}\right)$} \\
\hline & $\begin{array}{l}\text { Types of } \\
\text { Water } \\
\text { Extracts } \\
\end{array}$ & $\begin{array}{l}\text { DPPH }^{\bullet} \\
\text { Scavenging } \\
\text { assay } \\
\end{array}$ & $\begin{array}{l}\text { ABTS }^{\bullet+} \\
\text { Scavenging } \\
\text { assay } \\
\end{array}$ & $\begin{array}{l}\text { XO Inhibition } \\
\text { assay }\end{array}$ & $\begin{array}{l}\mathrm{O}_{2}{ }^{\bullet-}(\mathrm{X} / \mathrm{XO} \text { system }) \\
\text { Scavenging assay }\end{array}$ & $\begin{array}{l}\mathrm{O}_{2}{ }^{\circ-}(\mathrm{PMS} / \mathrm{NADH} \\
\text { system }) \text { Scavenging } \\
\text { assay }\end{array}$ \\
\hline \multirow{2}{*}{$\begin{array}{l}\text { Total } \\
\text { Polyphenols }\end{array}$} & HP-WCS & 0.9868 & 0.9906 & 0.9844 & 0.9866 & 0.9864 \\
\hline & MW-WCS & 0.9087 & 0.9643 & 0.9651 & 0.9551 & 0.9467 \\
\hline \multirow{2}{*}{$\begin{array}{l}\text { Total } \\
\text { Flavonoids }\end{array}$} & HP-WCS & 0.9933 & 0.9894 & 0.9223 & 0.9307 & 0.9326 \\
\hline & MW-WCS & 0.9810 & 0.9800 & 0.9791 & 0.9430 & 0.9518 \\
\hline
\end{tabular}

was a most active potent antioxidants and XO inhibitors irrespective of the method used for evaluation of free radical scavenging activity, superoxide radical scavenging activity and $\mathrm{XO}$ inhibition. Corn silk extract/tea can be prepared with microwave power heating rather than longer heating period as $2 \mathrm{~min}$ microwave heated extract solution provided higher total polyphenols, total flavonoids, Trolox equivalent antioxidants that were capable to show higher antioxidant and XO inhibition activities. In conclusion, for daily consuming water extracts of corn silk will serve a good source of antioxidant with health beneficial effects. However, further study is necessary to know the phytochemical profiles of corn silk water extracts.

\section{ACKNOWLEDGEMENT}

Authors greatly acknowledges the help of Marah Ismat, Khulood Ahmad, Zaynab Ali, Fatimah Safaa, Asra Majid, B.Pharm students of Dubai Pharmacy College (DPC) for the collection of raw corn/corn silk from supermarkets and in the sample preparation during carrying out this study. First author is thankful to Prof. Dr. Naglaa Gamil of DPC for providing the standard Rutin. 


\section{Conflict of interest}

Author declares no conflict of interest

\section{Funding}

None to declare

\section{Ethical approval}

None to declare

\section{Article info:}

Received July 3, 2020

Received in revised form November 6, 2020

Accepted December 9, 2020

\section{REFERENCES}

1. Erwin AT. Sweet Corn-Mutant or historic species?. Econ Bot. 1951;5:302-06.

2. Liu J, Wang C, Wang Z, Zhang C, Lu S, Liu J. The antioxidant and free-radical scavenging activities of extract and fractions from corn silk (Zea mays L.) and related flavone glycosides. Food Chem. 2011;126:261-69.

3. Maksimovic Z, Malencic D, Kovacevic N. Polyphenol contents and antioxidant activity of Maydis stigma extracts. Bioresour Technol. 2005;96:873-77.

4. El-Ghorab A, El-Massry KF, Shibamoto T. Chemical Composition of the Volatile Extract and Antioxidant Activities of the Volatile and Nonvolatile Extracts of Egyptian Corn Silk (Zea mays L.). J Agric Food Chem. 2007;55:9124-127.

5. Elliger CA, Chan BG, Waiss AC Jr, Lundin RE, Haddon WFC. Glycosylflavones from Zea mays that inhibit insect development. Phytochem. 1980;9:293-97.

6. Snook ME, Widstrom NW, Wiseman BR, Byrne PF, Harwood JS, Costello CE. New C-4"-hyroxy derivatives of maysin and 3'methoxymaysin isolated from corn silks (Zea mays). J Agric Food Chem. 1995;43:2740-45.

7. Nessa F, Ismail Z, Mohamed N. Phytochemicals from corn silk (Zea mays). J Trop Med Plants. 2001;2(2):189-92.

8. Ren SC, Liu ZL, Ding XL. Isolation and identification of two novel flavone glycosides from corn silk (Stigma maydis). J Med Plants Res. 2009;32:1009-15.

9. Hasanudin K, Hashim P, Mustafa S. Corn Silk (Stigma Maydis) in Healthcare: A Phytochemical and Pharmacological Review. Molecules. 2012;17:9697-715.

10. Zhang Y, Wu LY, Ma ZS, Cheng J, Liu JB. Anti-diabetic, antioxidant and antihyperlipidemic activities of flavonoids from corn silk on STZ-induced diabetic mice. Molecules. 2016;21 (1):7.

11. Guo J, Liu T, Han L, Liu Y. The effects of corn silk on glycaemic metabolism. Nutr Metab (Lond). 2009;6:47.

12. Zhao W, Yin Y, Yu Z, Liu J. Chen, F. Comparison of antidiabetic effects of polysaccharides from corn silk on normal and hyperglycemia rats. Int J Biol Macromol. 2012;50:1133-37.

13. Hu QL, Zhang LJ, Li YN, Ding YJ, Li FL. Purification and antifatigue activity of flavonoids from corn silk. Int J Phys Sci. 2010;5:321-26.

14. Hu QL, Deng Z. Protective effects of flavonoids from corn silk on oxidative stress induced by exhaustive exercise in mice. Afr J Biotechnol. 2011;10:3163-167.

15. Ebrahimzadeh MA, Mahmoudi M, Ahangar N, Ehteshami S, Ansaroudi F, Nabavi SF, et al. Antidepressant activity of corn silk. PhOL-Pharmacologyonline. 2009;3:647-52.

16. Velazquez DVO, Xavier HS, Batista JEM, Castro-Chaves CD. Zea mays L. extracts modify glomerular function and potassium urinary excretion in conscious rats. Phytomedicine. 2005;12: 363-69.
17. Wang K-J, Zhao J-L. Corn silk (Zea mays L.), a source of natural antioxidants with $\alpha$-amylase, $\alpha$-glucosidase, advanced glycation and diabetic nephropathy inhibitory activities. Biomed Pharmacother. 2019;110:510-17.

18. Ebrahimzadeh MA, Pourmorad F, Hafe S. Antioxidant Activities of Iranian Corn Silk. Turk J Biol. 2008;32:43-49.

19. Žilić S, Janković M, Basić Z, Vančetović J, Vuk Maksimović M. Antioxidant activity, phenolic profile, chlorophyll and mineral matter content of corn silk (Zea mays L): Comparison with medicinal herbs. J Cereal Sci. 2016;69:363-70.

20. Waiss AC, Chan BG, Elliger CA, Wiseman BR, McMillian WW, Widstrom NW, et al. Maysin, a flavone glycoside from corn silks with antibiotic activity toward corn earworm. J Economic Entomol. 1979;72:256-58.

21. Nessa F, Ismail Z, Mohamed N. Antimicrobial activities of extracts and flavonoid glycosides of corn silk (Zea Mays L). Int J Biotech Well Indus. 2012;1:115-21.

22. Habtemariam, S. Extract of Corn silk (Stigma of Zea mays) Inhibit the Tumour Necrosis Factor- $\alpha$-and Bacterial Lipopolysaccharide-Induced Cell Adhesion and ICAM-1 Expression. Planta Med. 1998;64:314-318.

23. Kim K, Shin HH, Choi SK, Choi HS. Corn Silk Induced Cyclooxygenase-2 in Murine Macrophages. Biosci Biotechnol Biochem. 2005;69:1848-53.

24. van Acker SABE, de Groot MJ, van Den Berg D-J, Tromp MNJL, Griffioen DH, Van Bennekom, et al. Structural aspects of antioxidant activity of flavonoids. Free Rad Biol Med. 1996;20:331-42.

25. Formica JV, Regelson W. Review of the biology of quercetin and related bioflavonoids. Food Chem Toxicol. 1995;33:10611080.

26. Saija A, Scalese M, Lanza M, Mazzullo D, Bonina F, Castelli F. Flavonoids as antioxidant agents: importance of their interaction with biomembranes. Free Rad Biol Med. 1995;19: 481-86.

27. Chebil L, Humeau C, Anthoni J, Dehez F, Engasser J-M, Ghoul M. Solubility of Flavonoids in Organic Solvents. J Chem Eng Data. 2007;52(5):1552-56.

28. Nessa F, Khan SA. Evaluation of antioxidant and xanthine oxidase inhibitory activity of different solvent extracts of leaves of Citrullus colocynthis. Pharmacognosy Res. 2014;6:218-26.

29. Kamtekar S, Keer V, Patil V. Estimation of Phenolic content, Flavonoid content, Antioxidant and Alpha amylase Inhibitory Activity of Marketed Polyherbal Formulation. J Appl Pharma Sci. 2014;4(9):61-65.

30. Khampas S, Lertrat K, Lomthaisong K, Suriharn B. Variability in phytochemicals and antioxidant activity in corn at immaturity and physiological maturity stages. Int Food Res J. 2013;20(6): 3149-57.

31. Alam, EA. Evaluation of antioxidant and antibacterial activities of Egyptian Maydis stigma (Zea mays hairs) rich in some bioactive constituents. J Am Sci. 2011;7:726-29.

32. Brand Williams, Cuvelier MC, Berset C. Use of a free-radical method to evaluate antioxidant activity. LWT. 1995;28:25-30.

33. Cos P, Ying L, Calomme M, Hu JP, Cimanga K, Poel BV, et al. Structure-activity relationship and classification of flavonoids as inhibitors of xanthine oxidase and superoxide scavengers. J Nat Prod. 1998;61:71-76.

34. Nessa F, Ismail Z, Mohamed N. Xanthine oxidase inhibitory activities of extracts and flavonoids of the leaves of Blumea balsamifera. Pharm Biol. 2010;48(12):1405-12.

35. Nagao A, Seki M, Kobayshi H. Inhibition of xanthine oxidase by flavonoids. Biosci. Biotechnol. Biochem. 1999;63:1787-90.

36. Malik N, Dhiman P, Khatkar A. In silico design and synthesis of targeted rutin derivatives as xanthine oxidase inhibitors. BMC Chemistry. 2019;13:71. 